\title{
Progress Toward Strengthening National Blood Transfusion Services - 14 Countries, 2011-2014
}

\author{
Michelle S. Chevalier, $\mathrm{MD}^{1}$; Matthew Kuehnert, $\mathrm{MD}^{2}$; Sridhar V. Basavaraju, MD²; Adam Bjork, PhD ${ }^{1}$; John P. Pitman, PhD ${ }^{1}$
}

Blood transfusion is a life-saving medical intervention; however, challenges to the recruitment of voluntary, unpaid or otherwise nonremunerated whole blood donors and insufficient funding of national blood services and programs have created obstacles to collecting adequate supplies of safe blood in developing countries (1). Since 2004, the U.S. President's Emergency Plan for AIDS Relief (PEPFAR) has provided approximately $\$ 437$ million in bilateral financial support to strengthen national blood transfusion services in 14 countries in sub-Saharan Africa and the Caribbean* that have high prevalence rates of human immunodeficiency virus (HIV) infections. CDC analyzed routinely collected surveillance data on annual blood collections and HIV prevalence among donated blood units for 2011-2014. This report updates previous CDC reports $(2,3)$ on progress made by these 14 PEPFAR-supported countries in blood safety, summarizes challenges facing countries as they strive to meet World Health Organization (WHO) targets, and documents progress toward achieving the WHO target of $100 \%$ voluntary, nonremunerated blood donors by 2020 (4). During 2011-2014, overall blood collections among the 14 countries increased by $19 \%$; countries with $100 \%$ voluntary, nonremunerated blood donations remained stable at eight, and, despite high national HIV prevalence rates, 12 of 14 countries reported an overall decrease in donated blood units that tested positive for HIV. Achieving safe and adequate national blood supplies remains a public health priority for $\mathrm{WHO}$ and countries worldwide. Continued success in improving blood safety and achieving WHO targets for blood quality and adequacy will depend on national government commitments to national blood transfusion services or blood programs through increased public financing and diversified funding mechanisms for transfusion-related activities.

During the last decade, PEPFAR has supported national blood transfusion services through the provision of technical and financial assistance to strengthen laboratory infrastructure, provide policy guidance, and promote the recruitment of voluntary, nonremunerated blood donors through donor selection strategies and expanded mobile collection campaigns. This support has contributed to reduced HIV prevalence among blood donors and increased blood collections. However, despite

\footnotetext{
*Botswana, Côte d'Ivoire, Ethiopia, Guyana, Haiti, Kenya, Mozambique, Namibia, Nigeria, Rwanda, South Africa, Tanzania, Uganda, and Zambia. Full list of countries receiving PEPFAR support (www.pepfar.gov).
}

continued advances in HIV testing of donated blood and blood products, the estimated incidence of newly diagnosed HIV infections associated with blood transfusion in middle- and low-income countries still remains as high as $1 \%$ to $3 \%(1)$.

During the 4-year surveillance period (2011-2014), national blood transfusion services ${ }^{\dagger}$ in the 14 PEPFAR-supported countries included in this report used a standardized data collection tool to report on three indicators of blood safety and adequacy: 1) the total number of whole blood units collected; 2) the percentage of units collected from voluntary, nonremunerated blood donors, and; 3) the percentage of donated units reactive for HIV. The rate of whole blood units collected per 1,000 population per year was calculated using national census estimates or United Nations population projections. Data on the status of national blood policies and blood transfusion services in the 14 countries were provided by WHO. Aggregated country data were analyzed and used to track changes in these indicators.

During 2011-2014, total annual blood collections by national blood transfusion services in all 14 countries increased $19 \%$, from $1,856,334$ units in 2011 to $2,203,190$ units in 2014 (Table 1). The overall median annual number of units collected increased $21.0 \%$ per year (range $=15.6 \%-32.7 \%$ ), with a wide range of increases among countries. For example, during 2011-2014, annual collections increased by $147 \%$ $(65,681$ units) in Ethiopia and by $15 \%$ (15,772 units) in Mozambique (Table 1). The rate of collections remained below WHO's minimum target for adequacy of 10 units per 1,000 population per year in all but four countries: Botswana, Guyana, Namibia, and South Africa. South Africa reached this target before the initiation of PEPFAR funding. The rate of collections in Botswana reached the target in 2005 (11 units per 1,000 population) (2), but declined to $<10$ units during 2011-2013. Guyana's collection rate reached 10.2 units per 1,000 population in 2009 (3), and achieved a peak of 14.6 units per 1,000 population in 2013. Namibia's collection rate reached 10.5 units per 1,000 population in 2011 , and increased to 12.7 units per 1,000 population by 2014 . Despite the variation, all four of these countries maintained collections

\footnotetext{
${ }^{\dagger}$ For the purposes of this report, "national blood transfusion services" refers to those government or non-governmental organizations with a legal mandate to collect, test, process, and distribute blood and blood components within a given country, and/or the legal authority to oversee or regulate the collection, testing, processing, and distribution of blood and blood components by other entities within that country.
} 
TABLE 1. Number of whole blood units collected by PEPFAR-supported blood transfusion services and units collected per 1,000 population, by country - 14 PEPFAR-supported countries, 2011-2014

\begin{tabular}{|c|c|c|c|c|c|c|c|c|c|c|}
\hline \multirow[b]{3}{*}{ Country } & \multicolumn{10}{|c|}{ Whole blood units per year } \\
\hline & \multicolumn{2}{|c|}{2003 (baseline) } & \multicolumn{2}{|c|}{2011} & \multicolumn{2}{|c|}{2012} & \multicolumn{2}{|c|}{2013} & \multicolumn{2}{|c|}{2014} \\
\hline & $\begin{array}{l}\text { No. } \\
\text { collected }\end{array}$ & $\begin{array}{c}\text { No. per } 1,000 \\
\text { population }\end{array}$ & $\begin{array}{l}\text { No. } \\
\text { collected }\end{array}$ & $\begin{array}{c}\text { No. per } 1,000 \\
\text { population }\end{array}$ & $\begin{array}{c}\text { No. } \\
\text { collected }\end{array}$ & $\begin{array}{c}\text { No. per } 1,000 \\
\text { population }\end{array}$ & $\begin{array}{l}\text { No. } \\
\text { collected }\end{array}$ & $\begin{array}{c}\text { No. per } 1,000 \\
\text { population }\end{array}$ & $\begin{array}{l}\text { No. } \\
\text { collected }\end{array}$ & $\begin{array}{c}\text { No. per } 1,000 \\
\text { population }\end{array}$ \\
\hline Botswana & 11,583 & 6.5 & 16,562 & 8.2 & 19,279 & 9.4 & 19,197 & 9.2 & 25,510 & 12.1 \\
\hline Côte d'Ivoire & 67,780 & 3.8 & 97,664 & 4.7 & 123,668 & 5.9 & 133,023 & 6.2 & 142,650 & 6.2 \\
\hline Ethiopia & 17,208 & 0.2 & 49,296 & 0.5 & 55,855 & 0.6 & 75,801 & 0.8 & 110,367 & 1.1 \\
\hline Guyana* & 4,008 & 5.4 & 7,930 & 10.5 & 7,712 & 10.3 & 11,148 & 14.6 & 10,260 & 13.4 \\
\hline Haiti & 8,711 & 1.0 & 19,751 & 2.0 & 25,608 & 2.5 & 27,439 & 2.7 & 28,486 & 2.7 \\
\hline Kenya & 40,857 & 1.2 & 126,123 & 3.1 & 156,891 & 3.8 & 169,369 & 3.9 & 182,187 & 4.1 \\
\hline Mozambique & 67,105 & 3.4 & 115,033 & 5.0 & 121,561 & 5.1 & 119,003 & 4.9 & 121,091 & 4.8 \\
\hline Namibia & 17,860 & 9.1 & 23,307 & 10.5 & 24,704 & 10.9 & 28,134 & 12.2 & 29,599 & 12.7 \\
\hline Nigeria $^{\dagger}$ & 1,266 & 0.0 & 39,106 & 0.2 & 42,577 & 0.3 & 55,288 & 0.3 & 49,328 & 0.3 \\
\hline Rwanda & 30,786 & 3.7 & 37,881 & 3.7 & 40,520 & 3.9 & 43,000 & 4.0 & 48,665 & 4.4 \\
\hline South Africa ${ }^{\S}$ & 809,322 & 17.4 & 943,810 & 18.1 & 925,647 & 17.5 & 947,024 & 17.7 & 956,968 & 17.7 \\
\hline Tanzania $^{\dagger}$ & 12,597 & 0.3 & 98,176 & 2.2 & 114,464 & 2.5 & 169,443 & 3.7 & 171,661 & 3.6 \\
\hline Uganda & 102,703 & 3.8 & 202,939 & 5.8 & 202,935 & 5.6 & 202,935 & 5.4 & 217,945 & 6.2 \\
\hline Zambia & 40,616 & 3.7 & 78,756 & 5.8 & 108,296 & 7.7 & 113,386 & 7.8 & 108,473 & 7.2 \\
\hline Total & $1,232,402$ & 2.3 & $1,856,334$ & 3.4 & $1,969,717$ & 3.6 & $2,114,190$ & 3.9 & $2,203,190$ & 4.1 \\
\hline
\end{tabular}

Abbreviations: AIDS = acquired immune deficiency syndrome; PEPFAR = President's Emergency Plan for AIDS Relief.

* Based on the 2013 United Nations Population Division census estimates. http://esa.un.org/unpd/wpp/DataQuery.

${ }^{\dagger}$ Nigeria and Tanzania established a national blood transfusion service in 2004; the first year for which 12 complete months of data were available was 2005 . Data from both countries only reflect blood collected by the National Blood Transfusion Service (NBTS) and do not include collections by private hospitals outside of the NBTS network. Private collections in both countries are believed to represent a substantial proportion of each country's national blood supply.

$\S$ Includes data on collections from South African National Blood Service and Western Province Blood Transfusion Services.

above the WHO target in 2014 (Table 1). During 2011-2014, population-based whole blood unit collection rates increased by $>1$ unit per 1,000 population in six countries: Botswana (3.9 units), Guyana (2.9), Namibia (2.2), Côte d'Ivoire (1.5), Tanzania (1.4), and Zambia (1.4) (Table 1). However, during 2011-2014, only three countries (Ethiopia, Haiti, and Tanzania) reported $>50 \%$ increases in collections, a decrease from the eight countries (Botswana, Guyana, Ethiopia, Haiti, Kenya, Mozambique, Uganda, and Zambia) that had reported $>50 \%$ increases in collections during 2004-2010 (2,3).

Ten countries ${ }^{\Im}$ reported having national blood policies in place by 2012, and all 14 countries reported having a national blood transfusion service that met WHO organizational criteria. By 2012 seven countries had published national standards for blood collection, testing, processing, and distribution. During 2011-2014, no change in the eight countries that previously reported collecting $100 \%$ of their national blood supply from voluntary, nonremunerated blood donors occurred (3) (Table 2). Ethiopia reported the largest increase in voluntary, nonremunerated blood donor donations, from 24\% in 2011 to $88 \%$ in 2014 . Guyana reported $99 \%$ voluntary, nonremunerated blood donor donations in 2014, an $11 \%$ increase from $89 \%$ in 2011 . However, after reporting progress during 2004-2010 (2,3), Tanzania, Haiti, and Mozambique reported declines of $10 \%, 36 \%$, and $37 \%$, respectively, in the

\footnotetext{
${ }^{\S}$ Botswana, Côte d'Ivoire, Ethiopia, Kenya, Namibia, Nigeria, Rwanda, South Africa, Uganda, and Zambia.

'Côte d'Ivoire, Ethiopia, Namibia, Nigeria, Rwanda, South Africa, and Zambia.
}

proportion of units collected from voluntary, nonremunerated blood donors during 2011-2014. The prevalence of HIVreactive donated whole blood units continued to decline in seven countries during 2011-2014, and stabilized at low levels in Namibia and South Africa (Table 3). During 2011-2014, five countries reported increases in HIV prevalence among donated units (Table 3). By 2014, despite continued high HIV prevalence among adults aged 15-49 years, 12 of 14 countries reported declines in HIV prevalence among donated blood units compared to baseline prevalence estimates at the start of the PEPFAR initiative (Table 3).

\section{Discussion}

Although increases in the percentage of voluntary, nonremunerated blood donors and in the number of blood units collected per 1,000 population since 2003 have been reported, whole blood collections largely remain insufficient to meet demand. Only four countries met the WHO-recommended minimum of 10 units per 1,000 population. The effect of the gap between supply and demand in many countries has been measured in pediatric and maternal mortality. As much as $65 \%$ of available blood in low-income countries in Africa has been estimated to be administered to children aged $<5$ years (1), and untreated postpartum hemorrhage is estimated to account for up to $46 \%$ of maternal deaths in some African settings (5). Unpublished 2012 data from the WHO Global Database on Blood Safety indicate that approximately 40 sub-Saharan African countries collect $<10$ units of blood per 
TABLE 2. Percentage of blood donations collected by PEPFAR-supported national blood transfusion services from voluntary, nonremunerated donors, by country - 14 PEPFAR-supported countries, 2003-2014

\begin{tabular}{|c|c|c|c|c|c|c|c|c|c|c|c|c|}
\hline \multirow[b]{2}{*}{ Country } & \multicolumn{12}{|c|}{$\%$ blood collections per year } \\
\hline & 2003 & 2004 & 2005 & 2006 & 2007 & 2008 & 2009 & 2010 & 2011 & 2012 & 2013 & 2014 \\
\hline Botswana & 100.0 & 100.0 & 100.0 & 100.0 & 100.0 & 100.0 & 100.0 & 100.0 & 100.0 & 100.0 & 100.0 & 100.0 \\
\hline Côte d'Ivoire & 100.0 & 100.0 & 100.0 & 100.0 & 100.0 & 100.0 & 100.0 & 100.0 & 100.0 & 100.0 & 100.0 & 100.0 \\
\hline Ethiopia & 38.8 & 27.5 & 23.2 & 28.1 & 28.4 & 20.5 & 29.8 & 23.5 & 24.2 & 17.1 & 35.5 & 87.8 \\
\hline Guyana & 21.7 & 18.9 & 26.1 & 31.2 & 61.1 & 54.6 & 84.0 & 78.5 & 89.0 & 86.0 & 96.0 & 99.0 \\
\hline Haiti & 5.2 & 5.4 & 14.9 & 27.4 & 51.9 & 65.8 & 69.5 & 83.9 & 70.0 & 71.8 & 59.1 & 52.5 \\
\hline Kenya & 99.0 & 95.3 & 97.6 & 98.9 & 99.5 & 100.0 & 100.0 & 100.0 & 100.0 & 100.0 & 100.0 & 100.0 \\
\hline Mozambique & 58.0 & 58.3 & 59.6 & 52.0 & 72.3 & 59.7 & 63.3 & 61.0 & 54.8 & 49.1 & 43.8 & 39.0 \\
\hline Namibia & 100.0 & 100.0 & 100.0 & 100.0 & 100.0 & 100.0 & 100.0 & 100.0 & 100.0 & 100.0 & 100.0 & 100.0 \\
\hline Nigeria* & - & - & 100.0 & 100.0 & 92.3 & 80.9 & 90.1 & 86.5 & 96.0 & 93.8 & 89.9 & 90.7 \\
\hline Rwanda & 100.0 & 100.0 & 100.0 & 100.0 & 100.0 & 100.0 & 100.0 & 100.0 & 100.0 & 100.0 & 100.0 & 100.0 \\
\hline South Africa ${ }^{\dagger}$ & 100.0 & 100.0 & 100.0 & 100.0 & 100.0 & 100.0 & 100.0 & 100.0 & 100.0 & 100.0 & 100.0 & 100.0 \\
\hline Tanzania* & - & - & 66.5 & 80.0 & 89.2 & 88.3 & 93.0 & 94.9 & 85.0 & 85.0 & 85.0 & 85.0 \\
\hline Uganda & 95.5 & 96.3 & 99.0 & 99.9 & 100.0 & 100.0 & 100.0 & 100.0 & 100.0 & 100.0 & 100.0 & 100.0 \\
\hline Zambia & 72.7 & 71.2 & 90.6 & 97.9 & 99.6 & 100.0 & 100.0 & 100.0 & 100.0 & 100.0 & 100.0 & 100.0 \\
\hline
\end{tabular}

Abbreviations: $-=$ not available; AIDS = acquired immune deficiency syndrome; PEPFAR = President's Emergency Plan for AIDS Relief.

* Nigeria did not have data on national blood policies available in the World Health Organization global database on blood safety in 2004. Nigeria and Tanzania established a national blood transfusion service in 2004; the first year for which 12 complete months of data were available was 2005.

+ Includes data on collections from South African National Blood Service and Western Province Blood Transfusion Services.

TABLE 3. Estimated population prevalence of human immunodeficiency virus (HIV) among persons aged 15-49 years, and percentage of collected whole blood units reactive for HIV, by country - 14 PEPFAR-supported countries, 2003-2014

\begin{tabular}{|c|c|c|c|c|c|c|c|c|c|c|c|c|c|c|c|}
\hline \multirow[b]{2}{*}{ Country } & \multicolumn{3}{|c|}{$\%$ HIV prevalence } & \multicolumn{12}{|c|}{$\%$ blood units reactive for HIV } \\
\hline & 2003 & 2008 & 2014 & 2003 & 2004 & 2005 & 2006 & 2007 & 2008 & 2009 & 2010 & 2011 & 2012 & 2013 & 2014 \\
\hline Botswana & 28.3 & 26.5 & 25.2 & 7.5 & 5.7 & 4.0 & 2.7 & 2.1 & 1.7 & 1.8 & 1.0 & 1.8 & 1.7 & 1.6 & 1.4 \\
\hline Côte d'Ivoire & 5.2 & 4.2 & 3.5 & 1.6 & 1.4 & 1.5 & 1.4 & 1.2 & 0.9 & 0.7 & 0.5 & 0.6 & 0.5 & 0.4 & 0.3 \\
\hline Ethiopia* & 2.6 & 1.6 & 1.2 & - & 3.6 & 3.4 & 2.5 & 3.0 & 2.9 & 1.8 & 1.9 & 3.7 & 2.0 & 1.6 & 0.8 \\
\hline Guyana & 1 & 1.4 & 1.8 & 0.8 & 0.6 & 1.0 & 0.6 & 0.3 & 0.5 & 0.2 & 0.2 & 1.6 & 0.7 & 0.4 & 1.0 \\
\hline Haiti & 2.8 & 2.2 & 1.9 & 1.7 & 1.8 & 1.6 & 1.9 & 1.4 & 1.7 & 1.4 & 1.2 & 1.1 & 0.9 & 1.1 & 1.1 \\
\hline Kenya & 7.9 & 5.9 & 5.3 & 1.5 & 1.7 & 1.9 & 2.5 & 1.2 & 1.5 & 1.2 & 1.0 & 0.5 & 0.5 & 0.6 & 0.7 \\
\hline Mozambique & 10.8 & 11.4 & 10.6 & 8.6 & 6.9 & 6.4 & 8.3 & 7.2 & 6.4 & 5.3 & 6.6 & 5.6 & 5.9 & 5.7 & 5.2 \\
\hline Namibia & 16.1 & 14.4 & 16 & 0.6 & 0.6 & 0.6 & 0.6 & 0.6 & 0.5 & 0.3 & 0.4 & 0.4 & 0.4 & 0.4 & 0.4 \\
\hline Nigeria $^{\dagger}$ & 3.7 & 3.6 & 3.2 & - & - & 3.8 & 3.5 & 2.5 & 1.8 & 2.2 & 2.1 & 2.1 & 1.9 & 1.8 & 1.6 \\
\hline Rwanda & 4.3 & 3.3 & 2.8 & 1.1 & 0.1 & 1.2 & 0.9 & 0.5 & 0.7 & 0.3 & 0.3 & 2.7 & 1.8 & 0.5 & 0.5 \\
\hline South Africa§ & 17.5 & 18.3 & 18.9 & $<0.1$ & $<0.1$ & $<0.1$ & $<0.1$ & 0.1 & 0.2 & 0.2 & 0.2 & 0.2 & 0.2 & 0.2 & 0.2 \\
\hline Tanzania $^{\dagger}$ & 7.4 & 6.4 & 5.3 & - & - & 4.8 & 3.2 & 2.8 & 3.3 & 2.2 & 1.2 & 0.8 & 1.0 & 1.0 & 1.3 \\
\hline Uganda & 6.4 & 6.6 & 7.3 & 2.0 & 1.9 & 1.6 & 1.5 & 1.3 & 1.2 & 0.8 & 1.0 & 0.9 & 0.5 & 0.6 & 1.1 \\
\hline Zambia & 14 & 13.2 & 12.4 & 6.9 & 6.4 & 9.0 & 6.4 & 3.8 & 4.2 & 3.5 & 4.8 & 4.0 & 3.4 & 3.8 & 3.5 \\
\hline
\end{tabular}

Source: 2003, 2008, and 2013 HIV prevalence data from UNAIDS estimates. http://aidsinfo.unaids.org.

Abbreviations: - = not available; AIDS = acquired immune deficiency syndrome; PEPFAR = President's Emergency Plan for AIDS Relief.

* In Ethiopia, reporting on HIV reactivity among collected units began in 2004.

† Nigeria and Tanzania established a national blood transfusion service in 2004; the first year for which 12 complete months of data were available was 2005.

$\S$ Includes data on collections from South African National Blood Service and Western Province Blood Transfusion Services.

1,000 population, and 25 of these countries collect less than half the units needed to meet minimum estimated transfusion requirements. To fill this gap, many countries collect blood from other types of donors, including family members or replacement donors (friends of the recipient who donate blood to replace the transfused blood). Although formal systems of paid donation have largely been eliminated in sub-Saharan Africa, family and replacement donors might still be driven by informal financial incentives ( 6 ); in addition, replacement donors who only donate once have been shown to carry a higher risk for transfusion-transmissible infections (7). Reliance on donors at higher risk for HIV infection underscores the importance of quality-assured laboratory screening with highly sensitive assays to provide additional safety, a requirement that recent studies have found is not always met in low-resource settings (8).

Although the majority of the 14 countries reported decreases in the percentage of blood units testing positive for HIV collected since 2003, HIV prevalence among donated units in all 14 countries remains higher than the $0.002 \%$ reported in high-income countries (1). Six of the 14 countries have HIV prevalence rates $\geq 1 \%$ among donated units, and two have rates $>3 \%$. Sustaining progress made in reducing the risk for transfusion-transmitted HIV in sub-Saharan Africa 
will depend in part on implementation of blood bank safety standards and quality management systems. However, to date, only two national blood transfusion services in sub-Saharan Africa (South Africa and Namibia) have achieved accreditation by an external accrediting body. To address this gap, the Africa Society for Blood Transfusion has developed the first regional standards and stepwise accreditation system for blood banks in sub-Saharan Africa. ${ }^{* *}$ Eleven countries have started the process and two have received certification.

The findings of this report are subject to at least three limitations. First, whole blood unit collections described in this report only reflect units collected by the national blood transfusion service in each country, and not units collected by individual hospitals. Although data are not available to quantify non-national blood transfusion service collections in all 14 countries, a recent CDC assessment of blood demand and use in Tanzania estimated that, in 2013, up to $38 \%$ of transfused units were collected by non-national blood transfusion service facilities (personal communication, B. Drammeh, CDC). As a result, total units collected per 1,000 population might be underestimated, and the proportion of blood supplied by voluntary, nonremunerated blood donors might be overestimated, because many of the countries in this report still rely on family and replacement donors to meet clinical demand. Second, variation in assays used for HIV screening, laboratory capacity, and testing proficiency among the countries might result in an over- or under- estimation of the HIV prevalence in collected units, which cannot be quantified. Finally, estimations of transfusion-associated HIV infections might underestimate the proportion of countries' overall annual HIV incidence attributable to unsafe blood, mainly because current incidence models do not account for test quality or rates of false negativity (9). Stronger donor selection criteria and improved screening technologies have reduced the number of HIV-positive donors being screened for donation and improved detection of HIV infections among donors, respectively $(10)$. However, in countries with high HIV prevalence, blood donor recruitment and mobilization of uninfected persons is an ongoing challenge.

Since the initiation of PEPFAR support in 2004, national blood transfusion services in 14 countries have made substantial progress in increasing blood collections and decreasing HIV prevalence among donated units, gains that stabilized during 2011-2014. As PEPFAR support for blood safety declines, ${ }^{\dagger \dagger}$ national governments need to continue to track key safety and adequacy indicators, and invest in sustainable

\footnotetext{
** African Society for Blood Transfusion (AfSBT) system of step-wise accreditation (http://www.afsbt.org).

$\dagger \dagger$ PEPFAR funding trends (https://data.pepfar.net/). Blood Safety programs are funded through the HMBL budget code.
}

\begin{abstract}
Summary
What is already known on this topic?

Countries supported by the U.S. President's Emergency Plan for AIDS Relief (PEPFAR) have made substantial progress toward safer and more adequate national blood supplies by reducing the prevalence of human immunodeficiency virus (HIV) among donated blood units, which has likely contributed to fewer transfusion-associated HIV infections. However, the risk for HIV transmission via transfusion remains high in low- and middleincome countries.

What is added by this report?

The safety and availability of blood products has increased in 14 PEPFAR priority countries in sub-Saharan Africa and the Caribbean. During 2011-2014, blood collections increased by $19 \%$, and despite high country prevalences of HIV infection, 12 of 14 countries reported an overall decrease in HIV prevalence among donated blood units. To reach World Health Organization 2020 goals for blood safety and adequacy, blood banking standards, accreditation, and quality management systems are still needed in low- and middle-income countries. What are the implications for public health practice?

As countries control other modes of HIV transmission, continued prevention of transfusion-associated HIV infections through the adoption and implementation of international safety standards and quality management systems will become increasingly important. Sustained progress will also rely on the development of reliable country-based funding models as external donor funding for blood safety is reduced.
\end{abstract}

quality management systems and studies to establish blood unit production costs. In addition, as countries make progress in controlling other factors of national HIV epidemics, expanded national HIV surveillance systems might aid in better understanding and tracking the contribution of blood transfusion to annual national HIV incidence.

\section{Acknowledgments}

National blood transfusion services and CDC country offices in Botswana, Côte d'Ivoire, Ethiopia, Guyana, Haiti, Kenya, Mozambique, Namibia, Nigeria, Rwanda, South Africa, Tanzania, Uganda, and Zambia; the WHO Blood Safety Programme, Geneva, Switzerland.

${ }^{1}$ Center for Global Health, Division of Global HIV/AIDS and Tuberculosis, CDC; ${ }^{2}$ National Center for Emerging and Zoonotic Infectious Diseases, CDC.

Corresponding author: Michelle Chevalier, MChevalier@cdc.gov, 404-639-6056.

\section{References}

1. World Health Organization. Blood safety and availability. Geneva, Switzerland: World Health Organization; 2015. http://www.who.int/ mediacentre/factsheets/fs279/en/.

2. CDC. Progress toward strengthening blood transfusion services-14 countries, 2003-2007. MMWR Morb Mortal Wkly Rep 2008;57:1273-7.

3. CDC. Progress toward strengthening national blood transfusion services-14 countries, 2008-2010. MMWR Morb Mortal Wkly Rep 2011;60:1577-82. 
4. World Health Organization. Voluntary non-remunerated blood donation. Geneva, Switzerland: World Health Organization; 2015. http://www.who.int/bloodsafety/voluntary_donation/en/.

5. Bates I, Chapotera GK, McKew S, van den Broek N. Maternal mortality in sub-Saharan Africa: the contribution of ineffective blood transfusion services. BJOG 2008;115:1331-9. http://dx.doi. org/10.1111/j.1471-0528.2008.01866.x.

6. World Health Organization. Towards $100 \%$ voluntary blood donation: a global framework for action. Geneva, Switzerland: World Health Organization; 2010. http://www.who.int/bloodsafety/ publications/9789241599696_eng.pdf.

7. Bloch EM, Vermeulen M, Murphy E. Blood transfusion safety in Africa: a literature review of infectious disease and organizational challenges. Transfus Med Rev 2012;26:164-80. http://dx.doi.org/10.1016/j.tmrv.2011.07.006.
8. Bloch EM, Shah A, Kaidarova Z, et al.; Anglophone Africa Transfusion Research Group. A pilot external quality assurance study of transfusion screening for HIV, HCV and HBsAG in 12 African countries. Vox Sang 2014;107:333-42. http://dx.doi.org/10.1111/vox.12182.

9. Prudden HJ, Watts $\mathrm{CH}$, Vickerman $\mathrm{P}$, et al. Can the UNAIDS modes of transmission model be improved? A comparison of the original and revised model projections using data from a setting in west Africa. AIDS 2013;27:2623-35. http://dx.doi.org/10.1097/01. aids.0000432476.22616.2f.

10. Basavaraju SV, Mwangi J, Nyamongo J, et al. Reduced risk of transfusion-transmitted HIV in Kenya through centrally co-ordinated blood centres, stringent donor selection and effective p24 antigenHIV antibody screening. Vox Sang 2010;99:212-9. http://dx.doi. org/10.1111/j.1423-0410.2010.01340.x. 